\title{
Case Report \& Review of the Literature \\ Duodenojejunostomy, an Old Technique but Novel Solution for Giant Duodenal Perforations - A Report of Four Cases and Review of Literature
}

\author{
Tiffany Rui Xuan Gan, Daniel Tan Ee Lee, Lee Chin Li and Jesse Hu Shulin*
}

Department of Surgery, Ng Teng Fong General Hospital, National University Health System, Singapore

\begin{tabular}{l} 
A R T I C L E I N F O \\
\hline Article history: \\
Received: 3 January, 2020 \\
Accepted: 20 January, 2020 \\
Published: 4 February, 2020 \\
\hline Keywords: \\
Giant ulcer perforations \\
duodenal ulcer \\
duodenojejunostomy
\end{tabular}

\begin{abstract}
A B S T R A C T
$\overline{\text { Background: Despite advances in the medical management of peptic ulcer disease, duodenal ulcer (DU) }}$ perforation remains a common surgical emergency. Most DU perforations are small and can be managed with omental patch repair. However, occasionally the surgeon may encounter a giant perforation not amenable to this. Giant DU perforations are defined as $>2 \mathrm{~cm}$. They are associated with high leak rates and mortality. Prognosis in elderly patients are particularly poor because of advanced age and comorbidities. Furthermore, there are no specific recommendations for their management despite a variety of repair techniques being described. Here, we aim to describe a novel technique used to treat such patients, especially those of advanced age, in our institution and to review the current literature.

Case presentation: Four patients with giant DU perforation underwent emergency laparotomy and repair with our duodenojejunostomy technique at our hospital. Post-operatively, patients were monitored clinically and radiologically and discharged when well and tolerating diet. The mean age of the patients was 67 years with an equal gender distribution. The average Charlson Comorbidity Index (CCI) score was 3 (moderately severe). All presented with peritonitis and two had concomitant bleeding. There were two anterior and two posterior ulcers. One was a revision repair after a leak post laparoscopic omental patch repair for the initial perforation. In all cases, the duodenojejunostomy repair technique was used. Post-operative recovery was uneventful for all except one who developed pneumonia. In particular; there were no anastomotic leaks, intra-abdominal collections, gastric outlet obstructions or mortalities.

Conclusion: Giant DU perforation remains a challenge to the general surgeon, particularly so in elderly patients with multiple comorbids. A review of the current literature suggests a myriad of surgical techniques but no perfect solution. Some suggested techniques include omental patch with pyloric exclusion, controlled tube duodenostomy, jejunal pedicled graft or serosal patch, gastric disconnection and partial gastrectomy. Here, we propose that isolated duodenojejunostomy can be a quick, safe and novel solution that ensures definitive repair of giant ulcer perforation in a single setting in the high-risk patient.
\end{abstract}

(C) 2020 Jesse Hu Shulin. Hosting by Science Repository.

\section{Background}

Peptic ulcer disease, which includes both gastric and duodenal ulcers, has had a major impact on morbidity and mortality until recently when there has been a fall in its incidence worldwide [1]. This decreasing incidence is due to the use of proton pump inhibitors and the treatment of Helicobacter Pylori infections [2, 3]. Nevertheless, despite advances in medical management of peptic ulcer disease and its lower overall incidence, the incidence of potentially life-threatening ulcer complications has not declined [4]. Duodenal ulcer (DU) perforation is one of the common complications of peptic ulcer disease. It remains a common surgical emergency because of its substantial risk of morbidity and mortality [5-8]. Most DU perforations are small and can be managed with omental patch repair $[9,10]$. However, occasionally the surgeon

${ }^{*}$ Correspondence to: Jesse Hu Shulin, Department of Surgery, Ng Teng Fong General Hospital, National University Health System, 1 Jurong East Street 21 , Singapore 609606; Tel: +6567166330; E-mail: jesse_hu@nuhs.edu.sg 
may encounter a giant perforation not amenable to this. Giant DU perforations are defined as $>2 \mathrm{~cm}[11]$. They are associated with high leak rates and mortality $[12,13]$. Prognosis in elderly patients are particularly poor because of advanced age and comorbidities [14, 15]. Furthermore, there is no specific recommendation for their management despite a variety of repair techniques being described $[12,16]$. Here, we aim to describe a novel technique used to treat such patients, especially those of advanced age, in our institution and to review the current literature.

\section{Case Presentation}

Four patients with giant DU perforation underwent emergency laparotomy and repair with our duodenojejunostomy technique at our hospital. Table 1 presents a summary of the four patients. The mean age of the patients was 67 years with an equal gender distribution. The average Charlson Comorbidity Index (CCI) score was 3 (moderately severe).

Table 1: Overview of Patients.

\begin{tabular}{|l|l|l|l|l|}
\hline Patient & $\mathbf{1}$ & $\mathbf{2}$ & $\mathbf{3}$ & $\mathbf{4}$ \\
\hline Gender & Female & Male & Male & Female \\
\hline Age & 75 & 52 & 62 & 79 \\
\hline Co-morbids & $\begin{array}{l}\text { Hypertension, Diabetes, } \\
\text { Hyperlipidemia, Previous } \\
\text { stroke }\end{array}$ & $\begin{array}{l}\text { Hypertension, Previous } \\
\text { Cholecystectomy }\end{array}$ & None & $\begin{array}{l}\text { Hypertension, Diabetes, } \\
\text { Hyperlipidemia } \\
\text { Ischemic Heart Disease }\end{array}$ \\
\hline $\begin{array}{l}\text { Charlson Comorbidity } \\
\text { Index Score }\end{array}$ & 5 & 1 & 2 & 4 \\
\hline Peritonitis & Present & None & Present & None \\
\hline Bleeding & Anterior D1 & Posterior D2 & Anterior D1 & Present \\
\hline Site of Ulcer & $2 \mathrm{~cm}$ & $3 \mathrm{~cm}$ & 2 cm & $2.5 \mathrm{~cm}$ \\
\hline Size of Ulcer & None & None & $\begin{array}{l}\text { Omental patch } \\
\text { repair done three } \\
\text { days prior }\end{array}$ & None \\
\hline Previous Repair & & & 11 & 8 \\
\hline Post-Op Length of Stay & 14 & 10 & None & None \\
\hline Post-Op Complications & Pneumonia & None & \\
\hline
\end{tabular}

\section{Description of Technique}

The duodenojejunostomy repair technique involves performing an upper midline laparotomy and thorough lavage of the entire peritoneal cavity. The perforation site is identified, and the proximal edge of the duodenal perforation is extended to the pylorus. A loop of jejunum is brought up in a retro-colic fashion and a hand-sewn side-to-side anastomosis with the loop of jejunum with $3 / 0$ Vicryl continuous suture is performed (Figure 1). A $24 \mathrm{Fr}$ drain is left in the right subhepatic area near the anastomosis and connected to passive drainage. Post-operatively, patients are monitored clinically and radiologically and discharged when well and tolerating diet.

\section{Case 1}

A 75-year-old Chinese female, with past medical history of hypertension, diabetes, hyperlipidemia and previous stroke (CCI Score 5), who was admitted for a fall suddenly presented with drowsiness, tachycardia, and severe metabolic acidosis. She was intubated and sent to the Intensive Care Unit (ICU) for monitoring. She was also noted to have right hypochondrial tenderness and increasing abdominal guarding. Chest X-Ray showed free air under the diaphragm. She hence underwent emergency exploratory laparotomy. Intra-operatively, there was a large amount of brownish fluid intra-peritoneally and a large $2 \mathrm{~cm}$ perforated ulcer on the anterior wall of the first part of the duodenum with fibrotic edges. She was hypotensive and tachycardic intra-operatively requiring inotropic support. The duodenojejunostomy repair technique as described above was used to repair the ulcer. She was transferred back to the ICU post-operatively and kept intubated. She was slowly weaned off inotropes and extubated on post-operative day (POD) 2. She was kept Nil Per Os initially but started on clear feeds on POD 4 with the diet slowly escalated after. The drain was removed on POD 7. On POD 8 however, she spiked a fever. Septic workup revealed a right sided pneumonia. Computed tomography of the abdomen demonstrated postoperative changes and was otherwise unremarkable. She was treated for pneumonia with a course of intravenous antibiotics. She remained well subsequently and was discharged on POD 14 to a community hospital for further rehabilitation. She remained well at subsequent clinic reviews.

\section{Case 2}

A 52-year-old Chinese male with past medical history of hypertension and previous cholecystectomy (CCI Score 1) was admitted for melena and haemodynamic instability. $\mathrm{He}$ underwent an oesophagogastroduodenoscopy and was found to have a bleeding and perforated ulcer on the posterior wall of the second part of the duodenum with a visible and actively bleeding vessel. He hence underwent emergency exploratory laparotomy. Intra-operatively, a bleeding and perforated $3 \mathrm{~cm}$ ulcer on the posterior wall of the second part of the duodenum was under-ran and the duodenojejunostomy repair technique as described above was performed. Post-operative recovery was uneventful. Patient tolerated escalation of diet well and haemoglobin levels remained stable. He was discharged on POD 10. 

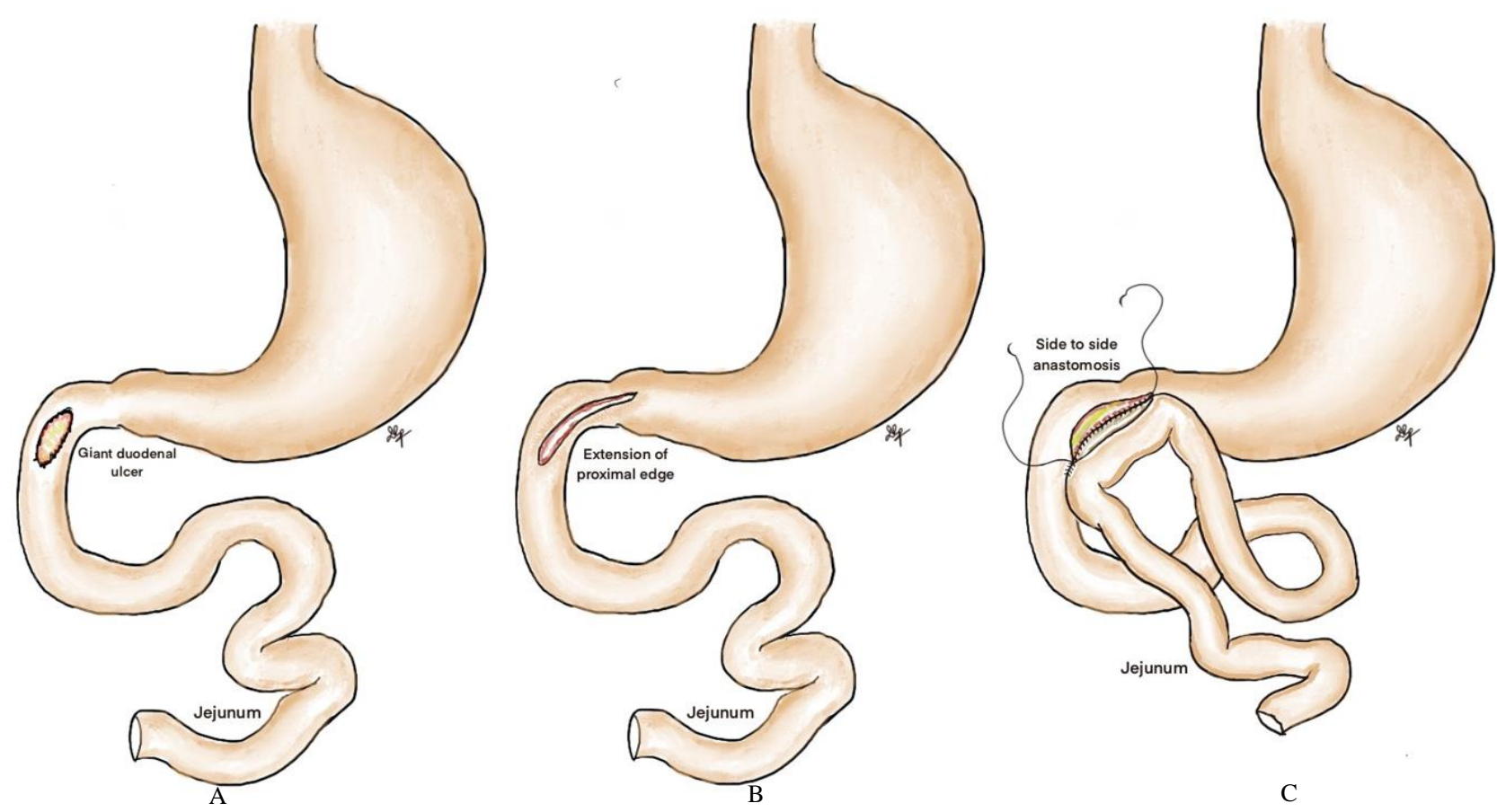

Figure 1: Illustration of the Duodenojejunostomy Technique.

A) Giant Duodenal Ulcer Perforation Site Identified; B) Extension of Proximal Edge of Ulcer Perforation to Pylorus; C) Hand-sewn Side-to-side Anastomosis with a Loop of Jejunum with 3/0 Vicryl Continuous Suture.

\section{Case 3}

A 62-year-old Chinese male with no known past medical history (CCI Score 2) was admitted for acute onset of severe epigastric pain. Chest Xray revealed free air under the diaphragm. He underwent emergency laparoscopic repair of a duodenal ulcer. Intra-operatively, a $2 \mathrm{~cm}$ perforated ulcer on the anterior wall of the first part of the duodenum was found with diffuse peritonitis and fibrinous exudate in the subdiaphgramatic areas. An omental patch repair was performed laparoscopically with interrupted Vicryl stitches and extensive washout done. The patient was started on sips of water post-operatively and continued on intravenous antibiotics. On POD 3 however, patient became febrile and tachycardic. Laboratory investigations revealed leucocytosis and elevated C-reactive protein levels. He also developed increasing abdominal tenderness and distension. A Computed tomography of the abdomen revealed extraluminal contrast tracking from the region around the first part of the duodenum to the gallbladder fossa. The patient hence underwent an exploratory laparotomy and revision of repair of the ulcer. Intra-operatively, the omental patch repair was found to be in situ but there was a small bile stained collection adjacent to the patch. Decision was made to revise the repair with the duodenojejunostomy technique as described above. Post-operative recovery was uneventful. He was discharged well and stable on POD 11.

\section{Case 4}

A 79-year-old Chinese female with a past medical history of hypertension, diabetes, hyperlipidemia, ischemic heart disease (CCI Score 4) presented with functional decline, coffee grounds vomitus and melena. She was hypotensive but fluid responsive. An oesophagogastroduodenoscopy was performed which revealed a large Forrest $2 \mathrm{~B}$ ulcer on the posterior wall of the first part of the duodenum that also appeared to be concomitantly perforated. She hence underwent emergency exploratory laparotomy. Intra-operatively, a large $2.5 \mathrm{~cm}$ perforated ulcer on the posterior wall of the first part of the duodenum eroding into the gastroduodenal artery was found. The ulcer was underran and repaired with the duodenojejunostomy repair technique as described above. Post-operative recovery was uneventful. Patient tolerated escalation of diet well and haemoglobin levels remained stable. She was discharged on POD 8.

\section{Conclusions - Discussion \& Review of Literature}

Duodenal Ulcer (DU) perforation is a common and serious complication of peptic ulcer disease [17, 18]. The management of perforated ulcer disease may be operative or non-operative. Conservative management also known as the "Taylor method" consists of nasogastric suction, starting on a regime of intravenous fluids, antibiotics, anti-secretory drugs and repeated clinical assessment [19]. The antibiotic regime should cover enteric gram-negative rods, anaerobes and oral flora. Although perforated ulcers may seal without operation in some patients, such an approach is associated with high morbidity and mortality, especially in elderly, high-risk patients like those in this case review [20]. Operative management of perforated DU also comprises appropriate resuscitation, intravenous hydration, analgesia and broadspectrum antibiotics. Most acute DU perforations are small, and the omental patch repair is regarded as the "gold standard" of treatment for such perforations $[9,21,22]$. In this technique, a strand of omentum is 
drawn over the perforation and held in place by full thickness sutures placed on either side of the perforation [23].

Giant DU perforation, however remains a challenge to the general surgeon and is considered as a distinct surgical entity [11, 13]. The presence of extensive duodenal tissue loss associated with surrounding inflammation and fibrosis results in high failure rates with the use of the standard omental patch repair [24].

A review of current literature suggests a myriad of surgical techniques but no perfect solution. Some suggested techniques include omental patch with pyloric exclusion, controlled tube duodenostomy, jejunal pedicled graft or serosal patch, gastric disconnection and partial gastrectomy [25-31]. Many of the techniques are complex and require a high degree of surgical expertise, which may not be available in the emergency setting. Furthermore, some of these techniques are time consuming. This may not be tolerated in elderly patients in poor general condition with hemodynamic instability and/or with significant comorbidity like those in our case review [27]. Post-operative leak is one of the most feared complications and leak rates remain high up to $13 \%$ with significant morbidity and mortality [12]. Many of the techniques above also do not address the other major complication seen in this group of patients which is gastric outlet obstruction [13].

Here, we propose a novel solution of using an old technique of isolated duodenojejunostomy to repair giant duodenal ulcer perforations. The availability of proton pump inhibitors means that definitive ulcer surgery is no longer indicated. Hence, the main aim of surgery in the emergent setting is to limit contamination of the peritoneal cavity and to repair the perforation. We believe that the leakage rate is minimized in our duodenojejunostomy technique as the healthy loop of jejunum improves the local conditions for healing. There is no risk of duodenal stump blowout as the duodenum is not transected. Furthermore, the risk of gastric outlet obstruction is minimized as the pylorus has been incised and the lumen of the duodenum is enlarged when a side-to-side anastomosis to the jejunum is performed. This technique ensures the definitive repair of the giant ulcer perforation in a single setting and avoids multiple procedures. It is technically less demanding which means it can be easily performed in an emergency setting and also quick which may be especially useful for high-risk elderly patients like those in our case review.

Post-operative recovery was uneventful for all except one of the patients in our study who developed pneumonia. In particular, there were no anastomotic leaks, intra-abdominal collections, gastric outlet obstruction or mortalities. We hence propose that our duodenojejunostomy technique can be a quick, safe and novel solution that ensures definitive repair of giant ulcer perforations in a single setting in the high-risk patient.
Abbreviation
DU: Duodenal Ulcer
CCI: Charlson Comorbidity Index
ICU: Intensive Care Unit
POD: Post-operative Day
TPN: Total Parenteral Nutrition

\section{Ethics Approval and Consent to Participate}

Not applicable, need for ethics approval and consent waived.

\section{Consent for Publication}

Not applicable.

\section{Competing Interests}

None.

\section{Funding}

None.

\section{Author Contributions}

Tiffany Gan Rui Xuan- Writing Original Draft, Daniel Tan Ee Lee, Lee Chin Li, Jesse Hu Shulin- Writing review and editing, supervision.

\section{Acknowledgement}

Pradeep Durai- Artwork for (Figure 1).

\section{REFERENCES}

1. Malfertheiner P, Chan FK, McColl KE (2009) Peptic ulcer disease. Lancet 374: 1449-1461. [Crossref]

2. Hermansson M, Ekedahl A, Ranstam J, Zilling T (2009) Decreasing incidence of peptic ulcer complications after the introduction of the proton pump inhibitors, a study of the Swedish population from 19742002. BMC Gastroenterol 9: 25. [Crossref]

3. Narayanan M, Reddy KM, Marsicano E (2018) Peptic ulcer disease and Helicobacter pylori infection. Mo Med 115: 219-224. [Crossref]

4. Lassen A, Hallas J, De Muckadell OB (2006) Complicated and uncomplicated peptic ulcers in a Danish county 1993-2002: a population-based cohort study. Am J gastroenterol 101: 945-953. [Crossref]

5. Søreide K, Thorsen K, Harrison EM, Bingener J, Møller MH et al. (2015) Perforated peptic ulcer. Lancet 386: 1288-1298. [Crossref]

6. Lau JY, Sung J, Hill C, Henderson C, Howden CW et al. (2011) Systematic review of the epidemiology of complicated peptic ulcer disease: incidence, recurrence, risk factors and mortality. Digestion 84 : 102-113. [Crossref]

7. Güzel H, Kahramanca S, Şeker D, Özgehan G, Tunc G et al. (2014) Peptic ulcer complications requiring surgery: what has changed in the last 50 years in Turkey. Turk J Gastroenterol 25: 152-155. [Crossref]

8. Møller M, Adamsen S, Thomsen R, Møller A, group PUPt (2011) Multicentre trial of a perioperative protocol to reduce mortality in patients with peptic ulcer perforation. Brit J Surg 98: 802-810. [Crossref]

9. Agarwal N, Gupta A, Jain B, Saran RN (2018) Omental Patch Repair for Duodenal Ulcer Perforation-Analysis of Factors Affecting Outcome: A Prospective Study. J Gastroenterol Pancreatol Liver Dis.

10. Malangoni MA (2009) Commentary: Perforated giant duodenal ulcers: what is the best treatment? Am J Surg 198: 324. [Crossref] 
11. Nussbaum MS, Schusterman MA (1985) Management of giant duodenal ulcer. Am J Surg 149: 357-361. [Crossref]

12. Gupta S, Kaushik R, Sharma R, Attri A (2005) The management of large perforations of duodenal ulcers. BMC surg 5: 15. [Crossref]

13. Newton EB, Versland MR, Sepe TE (2008) Giant duodenal ulcers. WJ Gastroenterol 14: 4995-4999. [Crossref]

14. Gokakin AK, Atabey M, Koyuncu A, Topcu O (2016) Peptic Ulcer Perforation in Elderly: 10 years' Experience of a Single Institution. Int J Gerontol 10: 198-201.

15. Christensen S, Riis A, Nørgaard M, Sørensen HT, Thomsen RW (2007) Short-term mortality after perforated or bleeding peptic ulcer among elderly patients: a population-based cohort study. BMC Geriatr 7: 8. [Crossref]

16. Vashistha N, Singhal D, Makkar G, Chakravarty S, Raj V (2016) Management of giant gastric ulcer perforation: report of a case and review of the literature. Case rep surg $2016: 4681989$. [Crossref]

17. Dakubo J, Naaeder S, Clegg-Lamptey J (2009) Gastro-duodenal peptic ulcer perforation. East African med J 86: 100-109.

18. Gunshefski L, Flancbaum L, Brolin R, Frankel A (1990) Changing patterns in perforated peptic ulcer disease. Am Surg 56: 270-274.

19. Chung KT, Shelat VG (2017) Perforated peptic ulcer-an update. World J gastrointestinal surg 9: 1-12. [Crossref]

20. Crofts TJ, Park KG, Steele RJ, Chung SS, Li AK (1989) A randomized trial of nonoperative treatment for perforated peptic ulcer. New England J Med 320: 970-973. [Crossref]

21. Arora BK, Arora R, Arora A (2017) Modified Graham's repair for peptic ulcer perforation: reassessment study. Int Surg J 4: 1667-1671.

22. Sharma D, Saxena A, Rahman H, Raina V, Kapoor J (2000) 'Free omental plug': a nostalgic look at an old and dependable technique for giant peptic perforations. Dig Surg 17: 216-218. [Crossref]
23. Graham RR (1937) The treatment of perforated duodenal ulcers. Surg Gyneco Obste 64: 235-238.

24. Jani K, Saxena A, Vaghasia R (2006) Omental plugging for large-sized duodenal peptic perforations: a prospective randomized study of 100 patients. South Med J 99: 467-472. [Crossref]

25. Vaughan III GD, Frazier O, Graham DY, Mattox KL, Petmecky FF et al. (1977) The use of pyloric exclusion in the management of severe duodenal injuries. Am J Surg 134: 785-790. [Crossref]

26. Lal P, Vindal A, Hadke N (2009) Controlled tube duodenostomy in the management of giant duodenal ulcer perforation-a new technique for a surgically challenging condition. Am J Surg 198: 319-323. [Crossref]

27. Ali WM, Ansari M, Rizvi SAA, Rabb A, Mansoor T et al. (2018) TenYear Experience of Managing Giant Duodenal Ulcer Perforations with Triple Tube Ostomy at Tertiary Hospital of North India. Indian J Surg 80: 9-13. [Crossref]

28. Gujar N, Sachin D (2013) Comparative Study Between Omental Plugging With Controlled Tube Duodenostomy for Management of Giant Duodenal Ulcer Perforation. Int J Sci Res

29. Bekele A, Kassa S, Taye M (2016) The Jejunal Serosal Patch Procedure: A Successful Technique for Managing Difficult Peptic Ulcer Perforation. East and Central African J Surg 21: 63-67.

30. Cranford Jr CA, Olson R, Bradley III EL (1988) Gastric disconnection in the management of perforated giantduodenal ulcer. Am J Surg 155: 439-442.

31. Kumar P, Khan HM, Hasanrabba S (2014) Treatment of perforated giant gastric ulcer in an emergency setting. World $J$ gastrointestinal surg 6: 5-8. [Crossref] 